\title{
INTERVENÇÃO PSICOSSOCIAL EM SAÚDE E FORMAÇÃO DO PSICÓLOGO
}

\author{
João Leite Ferreira Neto \\ Pontifícia Universidade Católica de Minas Gerais, Belo Horizonte, Brasil
}

\begin{abstract}
RESUMO: O artigo discute os temas "intervenção psicossocial" e "formação do psicólogo", a partir de um estudo de caso de uma experiência de intervenção desenvolvida numa escola do município Belo Horizonte, como uma ação da atenção básica em saúde. Apresenta a descrição detalhada do processo de intervenção, que teve duração de três anos. Conjuntamente, desenvolve a análise dessa experiência em diálogo com conceitos oriundos da análise institucional e da obra de Foucault. Enfatiza a função do interventor como coadjuvante de um processo, que tem como protagonista maior o próprio coletivo local, em detrimento das narrativas mais freqüentes que o descrevem como especialista que "vem de fora", favorecendo o fortalecimento da autonomia e autogestão desse coletivo. Discute também a importância de uma formação que aglutine as contribuições tanto do campo da psicologia clínica quanto da psicologia social, favorecendo o desenvolvimento de competências e habilidades plurais, para atuação em novas áreas.
\end{abstract}

PALAVRAS CHAVE: Saúde pública; intervenção psicossocial; formação do psicólogo; análise institucional; Foucault.

\section{PSYCHOSOCIAL INTERVENTION IN HEALTH AND THE PSYCHOLOGIST’S QUALIFICATION}

ABSTRACT: This paper discusses the topics of psychosocial intervention and the psychologist's qualification, analyzing a case study of an intervention experience developed in a school of Belo Horizonte as an action of primary care in public health. It presents a detailed description of the intervention process during three years of work. Concomitantly, it develops an analysis of this experience in dialoguing with concepts from institutional analysis and Foucault's work. It emphasizes the function of the intervener as a support role in the process, the local collective being the major protagonist, despite the frequent narratives that describe him as an "outsider" specialist with the task of empowering the group's autonomy and self-management. It discusses as well the importance of a qualification that brings together contributions from the field of clinic psychology and social psychology, favoring the development of multiple competencies and abilities for new areas of work.

KEYWORDS: Public health; psychosocial intervention; psychologist's qualification; institutional analysis; Foucault.

Este trabalho se propõe a discutir intervenção psicossocial e formação do psicólogo, a partir do estudo de caso de uma intervenção em saúde pública, na atenção básica em Belo Horizonte. Seu foco maior é uma intervenção realizada em uma escola estadual (escola de $1^{\mathrm{a}}$ à $4^{\mathrm{a}}$, contando à época com 700 alunos em 22 turmas), vizinha da unidade de saúde municipal, onde trabalhavam os profissionais que coordenaram as ações. O referencial teórico utilizado para a discussão da intervenção será, principalmente, retirado das contribuições da análise institucional (Baremblitt, 2002; Barros, s.d.) e da obra de Michel Foucault (1979). Além disso, será feita uma reflexão sobre a formação em psicologia, associada a essa experiência.

Os temas da intervenção psicossocial, da análise institucional e correlatos, têm grande importância para a psicologia social; e a apresentação, com certo nível de detalhamento, de "como" o processo foi conduzido, auxilia a produção de articulações teóricas com campos empíricos de pesquisa e intervenção. A retomada dessa prática de intervenção, ocorrida há mais de uma década (entre 1992 e 1994), se justifica na medida em que sua análise atualiza uma série de questões sobre a atuação e a formação dos psicólogos especialmente nas chamadas novas áreas de atuação (Conselho Federal de Psicologia [CFP], 1994), que, no caso da saúde pública, já nem é tão nova assim. Além disso, vários dos elementos presentes nessa experiência ainda reaparecem no relacionamento entre a saúde e a educação no setor público.

Diversos estudos apontam que a presença crescente dos psicólogos na saúde pública no Brasil aconteceu em associação com a Reforma Psiquiátrica, com a criação do 
campo chamado da saúde mental (Dimenstein, 1998; Ferreira Neto, 2004). Esse surto de crescimento ocorreu no contexto da crítica ao modelo asilar e com a criação do Programa de Saúde Mental. E a atividade precípua para o psicólogo no ambulatório era e ainda é pensada visando a atuação clínica junto aos pacientes portadores de transtornos graves e persistentes. Entretanto, uma vez colocados nas unidades de saúde, esses profissionais se defrontaram com uma série de outras demandas de atuação, entre as quais se destacava $o$ atendimento de crianças com problemas de aprendizagem e/ou comportamento. Parte dessa clientela vinha por encaminhamento diretamente da escola pública, mas, em grande parte das vezes, sem uma real necessidade de atendimento clínico. Eram crianças "trabalhosas" com as quais a escola não sabia lidar, desenvolvendo por isso um movimento de psicologização ou medicalização de seus problemas. Os profissionais ficavam entre duas alternativas: receber as crianças para atendimento endossando a demanda, ou recusar $\mathrm{o}$ atendimento reenviando os casos de volta à escola. A primeira alternativa é mais claramente imprópria, afinal "medicalizar ou psicologizar as dificuldades escolares é, via de regra, um encaminhamento historicamente ineficaz" (Boarini, 2000, p. 69). A segunda, mantém a criança num infeliz jogo de "empurra", no qual ninguém assume responsabilidades para ações resolutivas. Nosso projeto de intervenção buscou uma terceira via para esse impasse, através do compartilhamento de saberes, ações e responsabilidades, na invenção de novos modos de ação e realizando ruptura com práticas instituídas.

\section{Formação do Psicólogo}

A formação do psicólogo é um tema carregado de complexidades. A psicologia foi bem definida por GarciaRoza como sendo um "campo de dispersão de saberes" (s.d.). Se por um lado essa diversidade é produtora de uma formação mais rica e variada, por outro, trouxe uma tendência a uma segmentação partidarista em nossos cursos de formação. Em geral, ficamos divididos entre diferentes abordagens teórico-metodológicas, tendo áreas de atuação pensadas como universos estanques, além de sermos constantemente advertidos contra os perigos do ecletismo. Essa segmentação presente em nossos cursos, onde cada segmento só dialoga entre si, produz uma formação fragmentada e compartimentalizada (Ferreira Neto \& Penna, 2006).

Uma das dimensões mais curiosas dessa segmentação é a separação artificiosa entre os campos da psicologia clínica, tendo como objeto empírico hegemônico a intervenção individual, e o da psicologia social, tendo como objeto os grupos e os coletivos. A relação entre esses dois campos sempre foi marcada por uma indisposi- ção recíproca, a clínica retirando seu valor da suposta profundidade da intervenção e a social da suposta relevância social de suas intervenções. No entanto, o diálogo aberto e assumido entre esses campos aconteceu poucas vezes no Brasil, ainda que historicamente, no exterior ele ocorresse com certo vigor (Fernández, 2006). Além das diversas tentativas de arranjos freudo-marxistas, fortes nos anos de 1970, a história da construção desses campos de conhecimento e intervenção sempre foi marcada por hibridismos. Algumas breves indicações desse fato podem ser apontadas. Enquanto na Europa, em 1920, Freud escreveu seu texto Psicologia das massas e análise do eu em diálogo com teóricos sociais como Le Bon e McDougall, autor do primeiro livro sobre psicologia social (Freud, 1920/ 1976), nos Estados Unidos, após 1930, a influência das teorias de Freud leva a psicologia social americana a preocupar-se "cada vez mais, em formular uma psicologia exaustiva do leadership" (Mailhiot, 1981, p. 21). O próprio Kurt Lewin (1973) citava com freqüência conceitos freudianos em seus textos de relatos de pesquisas experimentais. Essa mesma fonte da dinâmica de grupos é retomada durante a guerra pelo trabalho do psicanalista inglês, Bion, e assim segue uma longa história de trocas e influências que não cabe aqui resenhar. Os exemplos citados fazem referência direta à psicanálise, pelo fato de ser uma abordagem de grande importância histórica no âmbito clínico da psicologia, e referência maior no âmbito da Reforma Sanitária no Brasil (Lobosque \& Abou-yd, 1998). Reconhecemos, no entanto, que apesar de ainda possuir certa hegemonia, a psicanálise não esgota o campo da psicologia clínica no Brasil.

No campo da saúde mental esse movimento de aproximação e distanciamento entre a psicologia clínica e a psicologia social toma uma forma própria. O Programa de Saúde Mental em Belo Horizonte sempre teve, como já foi dito, um modelo de atuação essencialmente voltado para uma atuação clínica. Entretanto, com o passar de tempo novas dimensões de atuação passaram a se impor com realce. Destacaria, entre outros, o acolhimento da demanda infantil e a interlocução maior com a Educação a partir da criação dos "fóruns regionais de Atenção à Saúde Mental da Criança e o Adolescente, com a participação de profissionais de saúde mental e da educação" (Lobosque \& Abou-yd, 1998, p. 255), implementados durante a gestão de municipal de 1993-1996. Mais recentemente, temos a integração das equipes de saúde mental com as equipes de saúde da família (Secretaria Municipal de Saúde [SMS], 2003), articulando atividades em conjunto. Nestas e em outras frentes de trabalho, a saúde mental desloca sua atuação de atenção eminentemente clínica, para desenvolver ações grupais e institucionais. Tendo em vista essa tendência, passaremos a narrar e analisar a mencionada experiência. 


\section{Histórico anterior à intervenção}

Apesar de ter sido iniciada em 1992, essa intervenção tem um histórico anterior que data de 1982. Desde aquela época, houve várias tentativas de um trabalho conjunto entre o centro de saúde e a escola estadual. Todas as tentativas foram marcadas pela falta de continuidade $\mathrm{e}$ falta de consenso nas propostas de trabalho a serem desenvolvidas.

Por um lado, a falta de continuidade era devida tanto às freqüentes e demoradas greves (ora na Escola Estadual, hora no Centro de Saúde Municipal) que interrompiam os trabalhos em andamento, quanto à rotatividade de funcionários, especialmente no cargo de direção da escola e da unidade de saúde. Por outro, as propostas de ambas as instituições sempre foram marcadas por um aparente antagonismo. Enquanto a escola pretendia garantir atendimento médico e psicológico aos alunos, por entender que fatores orgânicos e/ou psicológicos eram os determinantes principais dos problemas de aprendizagem, o centro de saúde pretendia implementar estratégias que envolvessem o corpo docente e funcionários da escola, deslocando a ênfase da consulta individual para práticas educativas coletivas, por entender que os fatores orgânicos e psicológicos não seriam os determinantes principais dos problemas de aprendizagem. Enfim, mesmo com reconhecimento de ambas as partes, do fato de possuírem uma clientela comum que se beneficiaria com um trabalho integrado entre o posto de saúde e a escola, o mesmo somente aconteceu em 1992, dez anos após as primeiras tentativas.

\section{Acolhimento da demanda e formulação das estratégias}

Em 1992, surgiu uma nova demanda por parte da escola, apresentada pela nova diretora, dirigida ao centro de saúde. Foi feita uma solicitação inicial centrada em duas questões. Primeiramente, os recorrentes problemas de aprendizagem e de manejo da disciplina com alguns alunos. Em segundo lugar, a alegação de dificuldade no trato com a sexualidade dos alunos, tanto em relação ao currículo (nas lições de "Biologia" para as turmas de $4^{\mathrm{a}}$ série), quanto em relação a manifestações ocorridas no espaço da escola (brincadeiras sexuais entre os alunos, palavrões, masturbação em sala, entre outras). Nossa preocupação inicial ao acolhermos esse pedido era a de evitarmos as dificuldades de continuidade das tentativas anteriores, evitando interrupções na continuidade do trabalho. O pediatra da unidade e eu vislumbramos uma estratégia que pudesse ultrapassar a simples prestação de serviços isolada por parte dos profissionais da saúde e, ao mesmo tempo, produzisse uma postura de co- responsabilização por parte dos profissionais da escola em relação ao processo de trabalho. O segundo objetivo era que esse processo tivesse princípio, meio e fim, evitando a criação de dependência em relação ao centro de saúde, e estabelecendo processos de auto-análise e autogestão (Baremblitt, 2002; Lapassade \& Lourau, 1972), que criasse condições de autonomia futura para o grupo de profissionais da escola.

Propusemos então a construção de um dispositivo que se mostrou fundamental durante todo o processo: um grupo multidisciplinar (GM), composto por funcionárias da Escola (diretora, especialistas e, ocasionalmente, professoras) e por funcionários do centro de saúde (psicólogo, pediatra, assistente social, e gerente). No grupo seriam discutidos tanto os problemas de aprendizagem, quanto as questões relativas à sexualidade, disciplina e outras dificuldades da Escola, com reuniões inicialmente semanais e posteriormente quinzenais. Dispositivo, segundo a Análise Institucional, é uma montagem que faculta a produção de inovações, que permite por "algo em funcionamento" (Barros, s.d., p. 75). Dito de outra maneira pela mesma autora, "o que caracteriza um dispositivo é sua capacidade de irrupção daquilo que se encontra bloqueado de criar, é seu teor de liberdade em se desfazer dos códigos" (Barros, 1996, p. 104).

Esse dispositivo, o grupo multidisciplinar - GM -, tornou-se o ponto de partida de nosso trabalho. Nossa primeira atividade consistiu na leitura e discussão de diversos textos que tratavam de temas ligados a problemas de aprendizagem, escritos por diferentes profissionais. De um modo geral, esses textos questionavam a medicalização e psicologização presentes na "invenção" dos quadros de Disfunção Cerebral Mínima e Hiperatividade. A idéia predominante na escola, de que os problemas de aprendizagem teriam como causa disfunções orgânicas ou dificuldades psicológico-familiares, passou a ser objeto de discussão. O resultado dessas discussões foi repassado ao corpo docente, numa carga horária menor, num segundo momento.

Decidimos também atender parcialmente a encomenda inicial de consultas médicas e psicológicas dos alunos "problema", depois de uma rodada inicial de discussões, obedecendo a um protocolo. Haveria um estudo de casos específicos de alunos portadores de problemas de aprendizagem, escolhidos a partir do diagnóstico das próprias professoras e das especialistas da escola (supervisoras e orientadora), através do seguinte protocolo: o caso era trazido ao grupo multidisciplinar pela professora do aluno e amplamente discutido. Segundo a avaliação do grupo, decidia-se pelo atendimento ou não do aluno pelo pediatra e/ou psicólogo, ou por uma estratégia não clínica de atendimento (realizado pela própria professora e/ou especialista). Assim sairíamos do emba- 
te antigo de quem é a responsabilidade dos problemas de aprendizagem, da saúde ou da própria escola, para investigarmos em conjunto essa problemática, a partir de uma casuística específica.

Finalmente, no âmbito desse processo foi elaborada uma estratégia de atuação frente às dificuldades das professoras no trato com a sexualidade dos alunos. A demanda inicial da escola de aulas sobre o assunto, a serem ministradas pelos profissionais do centro de saúde aos alunos, foi substituída pela realização de oficinas, onde o tema adolescência e sexualidade fosse trabalhado junto ao corpo docente e demais funcionários. Tínhamos como hipótese que as dificuldades alegadas eram oriundas não tanto de uma suposta falta de informação das professoras, mas sim da delicadeza inerente do próprio tema.

Tivemos, portanto, nesse momento inicial um acolhimento e uma "análise da demanda", entendida como "deciframento que se faz do pedido de intervenção por parte de uma organização" (Baremblitt, 2002, p. 136), alargando as possibilidades de trabalho para além da encomenda inicialmente colocada.

\section{Conceito de intervenção}

O conceito de intervenção é utilizado aqui não na acepção mais freqüente de um modo de se dirigir "à realidade do outro, interferindo nela e de alguma forma modificando-a" (Sarriera, Silva, Pizzinato, Zago, \& Meira, 2004, p. 20). Prefiro descrevê-lo na direção indicada por Foucault, "intervenção, no sentido etimológico em que intervir consiste em situar-se entre os elementos constitutivos de um contexto social" (Potte-Bonneville, 2006, p. 146), mais do que vir de fora para modificar a situação.

Foucault desenvolveu um experimento-intervenção junto às prisões francesas em fevereiro de 1971, através do Grupo de Informação sobre as Prisões - GIP. Sobre seu projeto, ele diz: "Trata-se de dar a palavra àqueles que têm uma experiência da prisão" (2003, p. 4). Dois anos mais tarde, Deleuze, um dos participantes do movimento, formulou o projeto político de Foucault, num diálogo conjunto entre ambos, dizendo-lhe: "você foi o primeiro a nos ensinar algo de fundamental: a indignidade de falar pelos outros" (Foucault, 1979, p. 72). A genealogia foucaultiana visava realizar um "acoplamento entre o saber erudito e o saber das pessoas" (1979, p. 171), trazendo a autonomia da ação de seus saberes e poderes, até então submetidos. $\mathrm{O}$ interventor, nesse caso, comparece mais como um agente catalizador e coadjuvante de um processo, que tem como protagonista maior o próprio coletivo local.

A descrição mais comum de que os interventores "intervêm no conjunto social, vindos de fora" (Macha- do, 2004, p. 15), ainda que seja empiricamente correta, quando enfatizada, enfraquece o objetivo maior de uma boa intervenção, ou seja, o de aumentar os índices de autonomia do grupo, seu empowerment ${ }^{l}$. A noção de intervenção, como um colocar-se entre os elementos constitutivos de um campo problemático, subverte a hierarquia presente na demarcação entre dois pólos: "os de dentro", que vivem os problemas e impasses, e "os de fora", que são convocados por supostamente deterem saberes-poderes privilegiados capazes de modificarem, através de instrumentos teórico-técnicos próprios, a situação local. Nessa condição por nós proposta, os "interventores" comparecem como coadjuvantes de um processo coletivo, onde os sujeitos envolvidos são considerados como sendo os mais capazes de afirmar, a partir de certa colaboração, onde estão os verdadeiros problemas. Foucault nos lembra que eles não precisam "que os ajudemos a 'tomar consciência", pois "a consciência está ali” (2003, p. 4); eles são os sujeitos da própria experiência e com certa assessoria saberão, com clareza, construir o desenho de seus próprios problemas e o arsenal de instrumentos para uma "ação possível" (p. 6). O que é preciso nesses casos é transformar a experiência pessoal em um saber político e coletivo capaz de promover mudanças. Destacar a dimensão coadjuvante dos interventores, externos ou internos ao coletivo-alvo, não desqualifica sua importância. Inúmeras práticas, inclusive a aqui discutida, demonstram a efetividade dessa função. Trata-se fundamentalmente de apontar que a ênfase na função do interventor como especialista, que promove a "conscientização" do grupo que lhe faz demandas, traz uma hierarquização de saberes e poderes, politicamente imprópria e empiricamente equivocada, afinal, quem sofre sabe melhor que ninguém qual é a face concreta do intolerável. Foucault considerava o interventor como "um relé para os grupos" se autonomizarem (2003, p. 7); essencial para fazer um circuito funcionar, mas que opera a partir das condições dadas pelo próprio circuito ou fazendo conexões com outros circuitos.

\section{Implementação das estratégias}

Para o planejamento e elaboração das oficinas, utilizamos como referência o trabalho desenvolvido no final da década de 1980, por uma ginecologista da rede pública, doutora Regina Caram, com os profissionais dos centros, intitulado "Oficina da Mulher". Sua metodologia subordinava a informação à participação, de maneira que os envolvidos se implicassem no processo. Inspirados nessa metodologia de participação, à qual havíamos nos submetido anteriormente, organizamos quatro encontros temáticos semanais, de modo a não haver interrupção continuada das aulas regulares, com duas horas de dura- 
ção, nos quais foram abordados os seguintes tópicos: identidade, sexualidade, planejamento familiar e doenças sexualmente transmissíveis (DST), e educação sexual. $\mathrm{Na}$ avaliação final, as professores acharam importante a experiência. Ainda que não tivessem recebido orientações "em pacote", como imaginavam inicialmente, aproveitaram a oportunidade para pensarem sua própria implicação como sujeitos, na função pedagógica. Além do mais, houve uma reflexão no sentido de que educação sexual não é apenas matéria de currículo, mas pode se dar em inúmeras situações da vida cotidiana, a partir das brincadeiras e conversas espontâneas dos próprios alunos, em conversas e ações informais por parte de professores e funcionários.

Enquanto as leituras e debates com o Grupo Multidisciplinar ocorriam, iniciamos paulatinamente o recebimento, pelo psicólogo e/ou pediatra, dos casos entendidos como problemáticos pelas professoras, obedecendo-se ao protocolo combinado. Nenhum aluno mais foi recebido diretamente, sem antes haver a discussão prévia do caso no GM com a respectiva professora. No primeiro ano recebemos e avaliamos quinze casos.

Fizemos então, em conjunto, um esboço de classificação desses casos em dois grandes grupos. O primeiro, de alunos que repetiam duas, três, quatro, até cinco vezes a mesma série. Neles, estava patente um quadro reativo de problema de aprendizagem, caracterizado por um total desinteresse em relação à escola, aliado à descrença na própria capacidade de aprender. $\mathrm{O}$ segundo grupo, de alunos iniciantes, 7 ou 8 anos, com desenvolvimento físico abaixo da média e quadro médico de recorrentes consultas. Nessa amostra inicial, não foi encontrado nenhum caso em que alguma disfunção médica e/ou psicológica fosse impedimento definitivo para o processo de aprendizagem, e apenas dois alunos necessitaram de tratamento psicoterapêutico. Percebeu-se, também, uma urgência maior por parte das professoras no encaminhamento de alunos que, além da dificuldade escolar, apresentavam, conjuntamente, problemas de comportamento e disciplina. Os alunos com baixo rendimento, mas "quietos", foram os últimos a serem encaminhados. Em decorrência desses dados, elaboramos um planejamento de trabalho para 1993, focalizando a conclusão de que a maior parte dos problemas de aprendizagem, no caso, a totalidade da amostra, demandava uma estratégia pedagógico-institucional, no contexto da própria escola. Para isso, a escola reivindicou junto à Secretaria Estadual de Educação, professoras especialistas, para trabalharem com esses alunos em atividades psicopedagógicas que fossem além da simples aula de reforço, no turno alternado ao que o aluno estava matriculado. Além disso, foi proposta uma segunda série de oficinas enfocando a questão da disciplina.

\section{O surgimento de analisadores}

Durante nosso processo coletivo de trabalho houve dois acontecimentos que portaram uma função de analisadores institucionais. Analisador é um acontecimento que revela a condensação de jogos de força oriundos de várias dimensões político-institucionais, permitindo operar mudanças na relação entre essas forças (Baremblitt, 2002). O acontecimento-Wellerson lançou luz sobre os efeitos perversos que a articulação saúde e educação pode trazer; e o acontecimento-Neuza ${ }^{2}$ evidenciou disfunções presentes nas tradições das escolas públicas no Brasil.

Comecemos pelo acontecimento-Wellerson. Durante o início de nosso trabalho, fui procurado no posto de saúde por uma mãe trazendo seu filho de 10 anos, Wellerson, diagnosticado como portador de oligofrenia, freqüentando há três anos uma escola especial, não estando ainda alfabetizado. Seu histórico de saúde incluía o uso de diversos psicofármacos, incluindo Haldol (droga utilizada no tratamento de psicoses), segundo a mãe, "receitado por um neurologista". A mãe, prudentemente, foi abandonando os diversos fármacos devido à ausência de resultados terapêuticos e excesso de efeitos colaterais. A despeito de tudo isso, ele tinha de cuidar da irmã mais nova, além de transitar pela cidade com segurança, sem se perder. Na entrevista comigo, o garoto tinha fluência verbal e compreensão intelectual comuns, apesar de não ser alfabetizado. Apresentei seu caso no GM, e as profissionais se dispuseram, com certo entusiasmo, a recebêlo como aluno regular na escola.

Inicialmente, a conduta escolar de Wellerson foi desastrosa. Inquieto, disperso e agressivo com os coleguinhas menores da $1^{\mathrm{a}}$ série. Ocorreram várias advertências e momentos de tensão. Entretanto, era nítido o empenho do coletivo escolar, ciente do projeto em curso, em apostar em sua possibilidade de melhora, o que, paulatinamente, aconteceu, não sem boa dose esforço, paciência, e condutas planejadas (ele foi convidado a tornarse auxiliar da professora no controle do restante da turma). Quatro anos mais tarde, já alfabetizado, Wellerson se formou na $4^{a}$ série. Essa experiência se constituiu num analisador privilegiado, revelando de um lado, o caminho perverso que a medicalização de queixas escolares, que em geral ocorre com a complacência e descaso por parte de outros agentes na saúde e na escola, produz sobre crianças e adolescentes. De outro lado, demonstrou a potência transformadora da qual a escola é portadora.

$\mathrm{O}$ segundo analisador, o acontecimento-Neuza, se apresentou durante o segundo ano de nosso trabalho. A prática comum das escolas estaduais era realizar a distribuição das turmas no início de ano respeitando o direito das professoras com mais tempo de casa escolher com qual turma iria trabalhar. Em grande parte das vezes, essa prática permite que professoras mais experientes traba- 
lhem com as turmas que possuem os melhores alunos, deixando as turmas problemáticas para professoras novatas. A mobilização promovida por nosso projeto de integração motivou uma das mais experientes e melhores professoras alfabetizadoras, que solicitou à direção da escola a montagem de uma turma de alunos repetentes para si própria no ano de 1993. Foram "selecionados" 23 alunos de $1^{\mathrm{a}}$ série, entre 8 e 11 anos, futuros candidatos à evasão escolar. No final, 18 dos 23 alunos foram alfabetizados, um número considerado surpreendente levandose em conta o perfil da classe.

Este analisador expõe, de um lado, a presença danosa de práticas corporativas defensivas, em detrimento de uma gestão desejável da organização escolar que vise o bem público e atinja o fim último da escola: a utilização de todo o processo de trabalho no aprimoramento da qualidade da aprendizagem. O valor instituído "tempo de casa", prevalecia sobre o valor transformador das práticas pedagógicas. De outro lado, demonstra o quanto pode ser dinamizadora a ruptura com os poderes instituídos, permitindo a emergência de movimentos instituintes transformadores.

\section{Algumas dificuldades}

A descrição do surgimento desses analisadores, a partir dos efeitos do dispositivo GM, não deve obscurecer as dificuldades que permearam todo o processo. A primeira delas era a força imobilizante do ritmo das rotinas de trabalho, tanto na escola quanto no centro de saúde. A necessidade de continuar lecionando ou atendendo a sofrida população do morro, funcionava frequentemente como um impeditivo para a invenção de alternativas de atuação fora das prescrições oficiais; afinal, o que justificaria a interrupção das aulas ou o cancelamento das agendas em função da criação de novas modalidades de enfrentamento dos problemas? O envolvimento ativo tanto da diretora da escola estadual quanto da gerente do centro municipal de saúde na época foi um fator crucial para a sustentação política de nosso projeto. Além disso, o engajamento e a disposição dos funcionários estaduais e municipais, efetivado através de ações que ultrapassavam o contrato de trabalho prescrito (que incluía pesquisa fora do horário de trabalho, participação em reuniões noturnas na escola para discussão com os pais de alunos sobre as propostas em curso, entre outras), foram fatores determinantes para a superação da força burocrática e imobilizante das prescrições do trabalho formal.

Outro elemento dificultador era a desvalorização, por parte dos poderes públicos, dos funcionários da educação e da saúde, através do pagamento de baixos salários e de condições de trabalho precárias. $\mathrm{Na}$ época, o salário das professoras era apenas uma fração a mais do salário mínimo vigente no País. Em decorrência disso, greves longas e alternadas, ora no estado, ora no município, eram freqüentes. Isso acarretava evidentemente longas interrupções em nosso processo de trabalho e a freqüente necessidade de retomadas.

Havia também o problema geral da formação dos profissionais. No caso das professoras, a maioria não possuía formação de nível superior e algumas eram profissionais em final de carreira, sem expectativas quanto às possibilidades transformadoras do próprio trabalho ("eu já vivi muito, sei onde isso vai dar..." ou "o problema é social e não há solução possível...”, são exemplos de falas corriqueiras). Percebia-se uma expectativa de rendimento e conduta sobre os alunos, a partir de parâmetros típicos de classe média idealizada, inadequados para a realidade onde trabalhavam. Era freqüente também a tendência de uma ação imediatista, pouco planejada a médio-longo prazo por parte da escola. Em todos os encontros sempre havia questões urgentes a serem resolvidas, sendo que o projeto necessitava de uma abordagem a médio e longo prazo. De outro lado, por parte dos profissionais de saúde, a formação era eminentemente clínica, voltada para a atenção individual e atendimento da demanda espontânea, faltando preparo para uma atuação multidisciplinar e interinstitucional. Outras questões sobre a formação, especialmente em psicologia, serão objeto de discussão mais à frente.

O projeto se constituiu para todos os envolvidos um espaço de formação continuada onde aprendíamos na medida em que fazíamos. Debalde todo o desgaste, interrupções, tensões entre demandas, negociações contínuas de prioridades, havia certo frescor e entusiasmo durante o processo, o que sempre nos permitia avançar.

\section{Disciplina e indisciplinas}

As queixas sobre a indisciplina dos alunos eram mencionadas com frequiência no GM. Já havíamos avaliado a indisciplina como fator determinante na escolha das crianças encaminhadas ao GM para atendimento. Decidimos, portanto, em 1993, pela realização de novo ciclo de oficinas, tendo a disciplina como eixo temático principal, realizado nos dois turnos. Desta vez, foram cinco encontros. Os quatro primeiros encontros teriam os seguintes focos: levantamento dos problemas de disciplina; discussão pragmática dos conceitos de autoridade e disciplina a partir da análise de dois regulamentos escolares, um conservador e outro ultra-liberal; discussão de um filme sobre o tema; apresentação e discussão de propostas de manejo da disciplina em sala de aula, incluindo a da realização de pequenas assembléias em sala com os próprios alunos. O encontro final foi uma grande assembléia com professores, direção, especialistas, funcionários e a equipe do centro de saúde. 
Na assembléia geral, estratégia utilizada na Análise Institucional, propusemos como tema central as dificuldades da escola em relação à disciplina. A dinâmica conduziu o próprio coletivo a estabelecer as regras de funcionamento. Houve eleição de um coordenador e dois relatores, inscrições para falar, marcação de tempo para cada fala e livre expressão para todos. Durante as discussões, dois elementos tornaram-se salientes. O primeiro, era que não havia para o grupo clareza quanto ao cumprimento das regras, e cada um agia à sua maneira, o que trazia grandes variações. No caso de aluno chegar atrasado ou sem uniforme, por exemplo, a decisão do que fazer dependia do estado de humor de quem estivesse no portão naquele dia. O segundo, era uma excessiva concentração das principais ações disciplinares na pessoa da diretora. A conduta, em geral, com o aluno indisciplinado era remetê-lo à sala da diretoria, sobrecarregando assim a diretora, além de esvaziar a autoridade da professora e dissociar a disciplina das práticas educativas em sala. A percepção desses elementos produziu impacto no grupo, e várias pessoas reagiram dizendo: "como podemos esperar disciplina dos alunos se nós próprios não a possuímos?" A partir daí, a assembléia se voltou para uma discussão, com caráter propositivo, sobre o modo de funcionamento e gestão do cotidiano escolar, enfatizando a gestão mais autônoma da disciplina dentro da própria sala de aula. Posteriormente, em 1994, o Regimento Escolar foi refeito com a inclusão de novo parágrafo: "Quando ocorrer atos indisciplinares dos alunos deverá ser discutido em assembléia em sala de aula, onde serão tomadas as decisões" (Escola Estadual D. Augusta Gonçalves Nogueira, 1994, p. 21).

\section{Algumas repercussões}

Nosso projeto teve duas etapas claramente definidas. Na primeira, a centralização das ações e reflexões no GM, espaço onde as questões eram abordadas numa atuação conjunta entre centro de saúde e escola. Essa etapa desaguou numa segunda, na qual as ações retornaram a seus lugares específicos, preservando-se assim a autonomia de ambos. As reuniões do GM foram extintas no final de 1994. Entretanto, a relação de interlocução e trocas entre escola e centro de saúde permaneceu. A escola adquiriu uma preocupação maior com a educação continuada do corpo docente e funcionários, além do maior reconhecimento dos fatores pedagógicos e institucionais presentes na emergência dos problemas de aprendizagem, aumentando sua responsabilização com a solução dos mesmos. A equipe do centro de saúde pode apreender o importante efeito das práticas de promoção de saúde. Houve, em decorrência do trabalho, a contenção da demanda "artificial" de consultas médicas e psicológicas. Além disso, o envolvimento numa prática de traba- lho multidisciplinar agregou a todos uma dimensão de formação pouco presente nas graduações, concomitantemente ao arejamento que um trabalho inventivo pode trazer ao cotidiano rotineiro.

\section{Considerações finais}

Dois aspectos merecem ser destacados dentro da análise desenvolvida. O primeiro, parte do reconhecimento que novos espaços de trabalho tem sido ocupados por psicólogos junto ao setor público e a organizações nãogovernamentais. Em geral, como ocorreu na experiência analisada na saúde pública, espera-se dos profissionais nesses novos espaços de atuação, o desenvolvimento de habilidades tanto da área clínica, quanto da área social (Ferreira Neto \& Penna, 2006, Kind, 2007). Hoje, os psicólogos são chamados a desenvolverem, de forma concomitante, ações sobre indivíduos e coletivos, objetos tradicionalmente segmentados na formação entre a tradição clínica da psicologia e a tradição social. Historicamente, a formação em psicologia tratou da diversidade inerente a nosso campo de modo a segmentar e compartimentalizar, teorias e métodos, diferentes áreas de atuação, diferentes abordagens. Enfim, os cursos tendiam a uma formação setorizada, enfatizando mais os antagonismos que as possibilidades de conexão, o que ainda não foi superado por completo. Cumpre aqui enfatizar a importância de entendermos os currículos dos cursos como um conjunto de experiências oferecidas ao estudante visando sua formação, cuja eficácia depende de certo nível de integração. Especialmente diante das novas áreas de atuação dos psicólogos, importa buscarmos, no conjunto das contribuições de nossos saberes e fazeres, instrumentos variados para construção de "competências e habilidades" (Brasil, 2004) plurais, ao mesmo tempo clínicas e sociais, necessárias para o enfrentamento da complexidade própria de nossa sociedade, ao mesmo tempo contemporânea e desigual.

A análise da experiência atualiza um segundo aspecto das práticas de intervenção: indica a necessidade de repensarmos a direção dada a este tipo de trabalho. Ao retirar o realce do lugar de especialista dos "interventoresespecialistas", em favor de sua função de "relé", de conector que propicia ao coletivo em questão o aumento de seus níveis de autonomia e empowerment, aponta importantes critérios ético-políticos a serem discutidos para avaliação da qualidade de uma intervenção.

\section{Notas}

1. Empowerment designa o movimento de ação social visando fortalecer o poder pessoal e coletivo de pessoas e grupos (Vasconcelos, 2003).

2. Ambos os nomes são fictícios. 


\section{Referências}

Baremblitt, G. (2002). Compêndio de análise institucional e outras correntes: Teoria e prática (5. ed.). Belo Horizonte, MG: Instituto Felix Guattari.

Barros, R. B. (1996). Dispositivos em ação: O grupo [Edição especial]. Cadernos de Subjetividade, 4, 97-106.

Barros, R. B. (s.d.). Institucionalismo e dispositivo grupal. In H. B. C. Rodrigues \& S. Altoé (Eds), Saúdeloucura 8: Análise institucional (pp. 65-78). São Paulo, SP: Hucitec.

Boarini, M. L. (2000). O psicólogo e a desinstitucionalização. In M. L. Boarini (Ed.), Desafios na atenção à saúde mental (pp. 65-77). Maringá, PR: Eduem.

Brasil. (2004, 19 fev.). Parecer final sobre as Diretrizes Curriculares Nacionais para os Cursos de Psicologia. Brasília, DF: Autor.

Conselho Federal de Psicologia. (1994) Psicólogo brasileiro: Práticas emergentes e desafios para a formação. São Paulo, SP: Casa do Psicólogo.

Dimenstein, M. D. (1998). O psicólogo nas Unidades Básicas de Saúde: Desafios para a formação e atuação profissionais. Estudos de Psicologia, 3(1), 53-81.

Escola Estadual D. Augusta Gonçalves Nogueira. (1994, 23 dez.). Regimento interno (pp. 1-21). Belo Horizonte, MG: Autor.

Fernández, A. M. (2006). O campo grupal: Notas para uma genealogia (Cláudia Berliner, Trad.). São Paulo, SP: Martins Fontes.

Ferreira Neto, J. L. (2004). A formação do psicólogo: Clínica, social e mercado. São Paulo, SP: Escuta.

Ferreira Neto, J. L., \& Penna, L. M. D. (2006). Ética, clínica e diretrizes: A formação do psicólogo em tempos de avaliação de cursos. Psicologia em Estudo, 11(2), 381-390.

Foucault, M. (1979). Microfísica do poder. (R. Machado, Trad.). Rio de Janeiro, RJ: Graal.

Foucault, M. (2003). Estratégia poder-saber (V. Ribeiro, Trad.). Rio de Janeiro, RJ: Forense Universitária.

Freud, S. (1976) Psicologia de grupo e análise do ego (J. Salomão, Trad.). In Edição Standart Brasileira das Obras Psicológicas: Vol. 18 (pp. 89-179). Rio de Janeiro, RJ: Imago. (Original publicado em 1920)

Garcia-Roza, L. (s.d.). Psicologia: Um espaço de dispersão do saber. Rádice Revista de Psicologia, 1(4), 20-26.

Kind, L. (2007) Aproximações entre a psicologia social e a saúde coletiva. In: Mayorga, C. \& Prado, M. A. M. (org). Psicologia Social: articulando saberes e fazeres. Belo Horizonte: Autêntica, pp. 255-269.

Lapassade, G., \& Lourau, R. (1972). Chaves da Sociologia (N. Caixero, Trad.). Rio de Janeiro, RJ: Civilização Brasileira.

Lewin, K. (1973). Problemas de dinâmica de grupo. São Paulo, SP: Cultrix.

Lobosque A. M., \& Abou-yd, M. (1998). A cidade e a loucura: Entrelaces. In A. Reis, D. Malta \& C. R. Campos (Eds.), Sistema Único de Saúde em Belo Horizonte: Reescrevendo o público (pp. 243-264). São Paulo, SP: Xamã.

Machado, M. N. M. (2004). Práticas psicossociais: Pesquisando e intervindo. Belo Horizonte, MG: Edições do Campo Social.

Mailhiot, G. B. (1981). Dinâmica e gênese dos grupos (5. ed.). São Paulo, SP: Livraria Duas Cidades.

Potte-Bonneville, M. (2006). Um mestre sem verdade? Retrato de Foucault como estóico paradoxal. In W. Koan \& J. Gondra (Eds.), Foucault 80 anos (pp. 129-150). Belo Horizonte, MG: Autêntica.

Sarriera, J. C., Silva, M. A., Pizzinato, A., Zago, C. U., \& Meira, P.
(2004). Intervenção psicossocial e algumas questões éticas e técnicas. In J. C. Sarriera (Ed.), Psicologia comunitária: Estudos atuais (2. ed., pp. 19-41). Porto Alegre, RS: Sulina.

Secretaria Municipal de Saúde de Belo Horizonte. (2003). Saúde mental na assistência básica. Grupo de trabalho Geas/integração Saúde Mental e Saúde da Família. Belo Horizonte, MG: Autor. Vasconcelos, E. M. (2003). O poder que brota da dor e da opressão: Empowerment, sua história, teorias e estratégias. São Paulo, SP: Paulus.

João Leite Ferreira Neto é Doutor em Psicologia Clínica pela Pontifícia Universidade Católica de São Paulo (PUC-SP) e Professor do mestrado em Psicologia na Pontifícia Universidade Católica de Minas Gerais (PUC Minas). Endereço para correspondência: Rua Planetóides, 271, Apto. 102, Santa Lúcia, Belo Horizonte, MG, 30 360-440. jleite.bhe@terra.com.br

\section{Intervenção Psicossocial em Saúde e Formação do Psicólogo}

João Leite Ferreira Neto

Recebido: 07/08/2007

$1^{\mathrm{a}}$ revisão: 16/09/2007

Aceite final: 09/11/2007 